ISSN: 0213-3563

https://doi.org/10.14201/azafea2021231338

\title{
REPENSANDO LOS DISCURSOS DEL ODIO Y SUS RECEPTORES A TRAVÉS DE LA ANIMALIZACIÓN Y SU PODER DISCURSIVO ESTIGMATIZANTE
}

\author{
Rethinking Hate Speeches and their Patients Through \\ Animalization and its Stigmatizing Discursive Power
}

\author{
Adrián PÉREZ \\ Magíster en Universidad de Salamanca
}

Enviado: 24 de agosto de 2021

Aceptado: 13 de septiembre de 2021

\section{RESUMEN}

A lo largo de nuestra historia, diferentes grupos de individuos han sido duramente perseguidos y estigmatizados en virtud de imágenes animalizantes. No obstante, pese a que este desprecio cobra todo su sentido si atendemos al profundo rechazo, odio y asco, que acompaña a determinadas iconografías animales empleadas para mancillar a estos grupos de humanos, menores han sido los esfuerzos académicos por reconocer a los animales como auténticos receptores de los discursos y sus consecuencias. Tomar en consideración si verdaderamente estos pueden serlo y en qué términos, son los objetivos principales de esta investigación.

Palabras clave: Discursos del odio; explotación; instrumentalización; ética animal.

\section{ABSTRACT}

Animalization has usually been conceived as one of the most powerful hate speech strategies. This is partly due to the fact that it operates by reducing and comparing certain minority human groups with the most undesirable, execrable and wretched animal iconographies; and spreads contempt and other forms of hatred in order to dehumanize the other. Even though this strategy carries biases and prejudices based on a deeply rooted specist tradition that only see creatures like cockroaches, pigs, rats or ticks, as filthy 
plagues or dirty vermins, animals themself have not been contemplated as real hate speech receivers. Understanding if we can, or we cannot hate animals with our speeches, is the main purpose of this paper.

Key words: Hate speech; exploitation; instrumentalization; animal ethics.

\section{INTRODUCCIÓN}

Desde la literatura especializada en los discursos del odio se ha prestado un interés particular a la animalización como estrategia discursiva deshumanizante. Comparar al otro con un animal, y más concretamente, con aquellos revestidos por una iconografía profundamente denostada en nuestra cultura como ratas, ratones, cucarachas o garrapatas, parece haberse convertido en una maniobra recurrente orientada a humillar y menoscabar la integridad moral de aquellos contra los que se dirige (Patterson, 2008; Kovacevic, 2017; Schuster, 2019; Pons, 2015). Atendemos a una herramienta extremadamente dúctil y versátil, que, desde una sobredimensionada presencia en nuestra tradición, ha sido empleada para desprestigiar a grupos tan variados como políticos, mujeres u homosexuales entre muchos otros.

Tomando en consideración la profunda complejidad que atraviesa a esta asociación estigmatizante, y sin la intención de desestimar ninguna de las intrincadas aristas que la constituyen, podemos afirmar sin ambages que uno de los campos de análisis que mayor atención académica ha recibido en virtud de sus estrepitosas consecuencias, lo encontramos en diferentes discursos del odio vertidos durante determinados conflictos bélicos tales como guerras, dictaduras o genocidios. Diego Andrés Andueza Kovacevic (2017) ha destacado que algunos de los más importantes a este respecto podemos rastrearlos en la Alemania nazi de Hitler, son estos la Italia fascista de Mussolini o la dictadura militar chilena de Pinochet. Siendo estos tan solo tres ejemplos de una lista mucho más amplia de conflictos armados, donde de manera cla$\mathrm{ra}$, las atribuciones animalescas han sido empleadas para arremeter de forma violenta contra el enemigo.

El genocidio ruandés constituye claramente otro de los ejemplos más representativos en los que la animalización ostentó un papel relevante, y así nos lo hace saber Yona Schuster a través de su investigación. Para corroborar este planteamiento, la autora expone cómo durante este los tutsis fueron frecuentemente equiparados a serpientes, hienas, ratas, cucarachas y otros insectos. Una serie de atribuciones que facilitarían el exterminio al disminuir el sentimiento de culpabilidad de sus perpetradores a través de imágenes animaliza- 
das que no contemplaban estar aniquilando a otro igual, a otro humano, sino a una forma de existir devaluada e insignificante. Schuster (2019) sostiene que cuando los medios de comunicación pro-hutu alentaban a la población a acabar con esas inyezi (cucarachas), actuaban concienzuda y premeditadamente relacionándolos con un animal que "provoca una sensación de asco y desagrado tan fuerte, que matarla es una reacción casi inmediata, automática; se rastrea hasta eliminarse" (p. 39). Todo ello apunta a que la selección de los ejemplares elegidos para menospreciar, vejar y perseguir a los tutsis, no se produjo en ningún caso de manera arbitraria o azarosa, pues estos fueron comparados con un conjunto de criaturas a las que la población receptora del discurso parecía estar ya acostumbrada a temer, perseguir y odiar.

A mi parecer, otra de las investigaciones que con mayor rigor y seriedad recoge el empleo de estas y otras imágenes animalescas utilizadas para someter y menospreciar al enemigo, lo encontramos en el pensamiento de Charles Patterson (2008), quien sostiene que "denominar animales a la gente es siempre una señal ominosa porque les predispone a ser humillados, explotados y masacrados” (p. 58). En ese sentido, junto con los ejemplos hasta aquí presentados, este autor expone otra serie de casos verdaderamente representativos donde dicha estrategia ha sido empleada con fines hostiles como en las guerras de Injun en Filipinas, del Golfo, de Vietnam, o en los procesos colonizadores de América y África. Remitiendo a este último contexto, Patterson expone cómo los africanos fueron comparados ya desde el siglo XVI con simios y "otras bestias" por los viajeros europeos, que acostumbraban a describirlos como criaturas feas, horrendas y sucias. Pero no solo eso, en su estudio también rastreamos otra serie de pronunciamientos, discursos y textos publicados por auténticas afamadas y bien reconocidas eminencias de los siglos XVII, XVIII y XIX como Charles Lyell, Edward Long, Thomas Herbert o Georges Cuvier, quienes vilipendiaron de manera pública y recurrente a diferentes tribus africanas como los bosquimanos o los hotentotes. Tomando como referencia a este último científico y pionero de la ciencia anatómica comparada, Patterson (2008) describe al detalle cómo:

Cuando la mujer africana conocida como "la Venus hotentote" murió en París, Cuvier escribió que hacía morritos con sus labios exageradamente carnosos, lo hacía "exactamente en el mismo modo en que he observado hacerlo a los orangutanes" y que se movía con un aire "que le recordaba a un simio a uno". Sacó la conclusión de que tenía las características de un animal. "No he visto jamás una cabeza humana que se pareciese tanto a la de un mono como la de esta mujer" (Gould, 2003, p. 69) (en Patterson, 2008, p. 60). 
Otros investigadores como Steve Best (2015) o el recientemente mencionado Kovacevic (2017), aunque remitiendo a otros contextos, han reforzado este planteamiento. Ambos aseveran que, una vez determinados colectivos humanos se ven redimensionados y degradados mediante las estigmatizaciones que rodean al denigrado espectro animal, también quedan potencialmente expuestos a las mismas formas de control, dominio o explotación que hemos empleado para someter a estos últimos, y que han gozado en Occidente de una apabullante permisibilidad y tolerancia. $O$ en otras palabras, en los discursos del odio que emplean esta estrategia discursiva, las lógicas de dominación instrumental que justifican y legitiman la subordinación, inferioridad y servidumbre de los animales, actúan como auténticos sustentáculos que impulsan un nuevo proyecto discursivo que pretende desplazar a nuevos grupos de humanos al mismo plano devaluado en el que ya se encontraban recluidos estos seres sintientes. Tales aportaciones apuntan a que la animalización alcanza su máximo potencial discursivo al extender, y no al crear, un odio previo y unas connotaciones peyorativas y denigrantes provenientes de una ignominiosa iconografía animal. La existencia de un imaginario fuertemente especista, antropocéntrico y sólidamente aceptado, parece erigirse como un claro antecedente que no puede eludirse si se busca comprender de manera crítica cómo ha operado esta herramienta en los discursos.

Estimo, sin embargo, que las investigaciones tradicionales han tendido a abordar el odio hacia los animales solo de manera colateral y residual en la medida que este incidía sobre los grupos humanos excluidos, y no tanto desde el verdadero interés en sí mismo que realmente presenta. Pese a que, como veremos, el estatuto de receptor de los discursos del odio ha quedado deliberadamente limitado a los seres humanos, la hipótesis aquí sostenida repara en que también podemos odiar a los animales al menos desde un sentido despectivo y cosificador. Es decir, la animalización no solo ha sido empleada para denostar a grupos y colectivos humanos como los hasta aquí expuestos.

Ratas voladoras o cucarachas de aire son tan solo dos etiquetas dentro de un maremágnum de atribuciones estigmatizantes bajo las cuales nuestra cultura popular ha calificado de manera recurrente a las palomas. Dos expresiones que además, no solo se han visto atravesadas por un profundo y abrupto sentimiento de rechazo que contempla a las tres como seres abyectos, sucios y deleznables, sino también por una clara declaración de intenciones por perseguirlas arremetiendo contra ellas de forma violenta e indiscriminada. Prueba de ello son las beligerantes técnicas de exterminio empleadas y legitimadas durante décadas, y cómo en su obstinado ejercicio por erradicarlas y aniquilarlas a cualquier precio, no tomaron en consideración parámetros tan relevantes como el sufrimiento animal provocado, o las posibles implicaciones 
que algunos de los insecticidas y tóxicos empleados pudieran provocar en la naturaleza y el medio ambiente. Actualmente algunos de los frecuentemente utilizados, como el endrin, el aldrin o el cholrdane, han sido expresamente prohibidos por tales motivos (Ogg et al., 2006).

Plantear que este incesante asedio ha podido perpetrarse en nuestro pensamiento de forma tan prolongada sin la existencia de un discurso altamente sistematizado que lo haya estructurado, promovido e impulsado, resulta cuanto menos cuestionable. Y con ello, también resultaría problemático negar los claros paralelismos existentes entre las retóricas genocidas recientemente presentadas, y aquellas otras que durante tanto tiempo buscaron exterminar, arrollar y aniquilar a determinados grupos y especies animales en virtud del intenso odio que se sentía -y se siente en la actualidad- hacia ellos.

Como tendremos oportunidad de contrastar, los ejemplos a los que podemos recurrir para mostrar la existencia de estas conflictivas similitudes son francamente inagotables. Para comenzar, podemos remitir a los propios manuales y escritos destinados a la promoción de técnicas de exterminio de algunos animales de plaga como los recientemente expuestos -ratas, cucarachas...-, y cómo su persecución y hostigamiento se ve fomentada en virtud de sesgos, prejuicios y caricaturizaciones. El "Manual para el control de cucarachas" es uno de los casos más evidentes al respecto, ostentando una relevancia particular algunos de los capítulos y epígrafes que lo componen tales como "¿Que muerdan el polvo!”, o "Conozca a su enemigo”, así como un conjunto de imágenes burlescas que muestran de manera clara que la persecución de estas criaturas también se ha producido a través de atribuciones estigmatizantes, que tal y como acontecía durante los genocidios, apuntan a justificar y aproblematizar el exterminio (Ogg et al., 2006).

Pero más extensamente, el discurso del odio hacia los animales puede rastrearse de modo mucho más explícito en determinadas publicaciones digitales en la Red en las que estos animales son cruelmente torturados (The UZ, 2021a; Neild D, 2019). Una serie de vídeos de acceso público en portales web como YouTube, materializan los discursos del odio en un maquiavélico proyecto audiovisual. Entre los más destacados podemos distinguir vídeos en los que ratones vivos son atravesados por cuchillas y clavos (Wilderness xyz, 2019; The UZ, 2021b), u otros en los que cucarachas son lanzadas violentamente contra la pared o perseguidas con sopletes hasta quedar completamente calcinadas (Kõivupuu, 2021). Detrás de tales acontecimientos se esconde una comunidad de internautas que plasma con sus comentarios el profundo odio que comparten con el creador del vídeo, así como su imperiosa necesidad por continuar deleitándose con un contenido que parece no atisbar límite alguno a la morbosidad y al sadismo. 
No obstante, también podemos distinguir entre los discursos en sí mismos y otros actos o expresiones prácticas cuyo móvil también es el odio, pero donde este último puede tener un origen completamente ajeno al discurso. Sabiendo esto, si bien no resulta imprescindible comprender los vídeos aquí presentados como auténticos discursos, la apertureidad comunicativa y espacio dialógico sobre el que los espectadores proyectan sus macabras y maquiavélicas fantasías, difícilmente podría ser catalogado como algo distinto a un execrable discurso del odio. Como tendremos oportunidad de comprobar en el apartado final de esta investigación, la tortura y el odio han encontrado un espacio público en el que proliferar sin oposición, y tal acontecimiento exige una revisión ulterior que nos permita hacerle frente de manera efectiva.

Ahora bien, con la intención de poder atender críticamente a tales hipótesis, hemos de aclarar previamente cuáles han sido las argumentaciones vertidas que han impedido presentar a los animales como auténticos receptores de los discursos, así como reflexionar sobre si este desplazamiento continúa siendo justificable a día de hoy sin apelar a convicciones sesgadas o a creencias subjetivas.

\section{Discursos Del odio: UnA Delimitación CONCEPTUAL}

Con independencia del enfoque metodológico -filosófico, jurídico, psicológico, etc- desde el que se aborde una aproximación a los discursos del odio, un punto de convergencia que emerge en todos ellos y que merma las posibilidades por establecer una definición consensuada y universalizable de los mismos, consiste en la seria dificultad por acomodar, de manera clara y estable, unos criterios lo suficientemente precisos como para discernir dentro de un profuso y heterogéneo sustrato social, no solo qué prácticas han de quedar recogidas de manera irrevocable bajo este prisma conceptual, sino también cuáles no lo hacen y los motivos y justificaciones que puedan avalar tal decisión sin erigirse en una propuesta unilateral y sesgada (Bazzaco et al., 2018).

En gran medida, según lo han entendido Edoardo Bazzaco et al. (2018), dicha coyuntura obedece al preponderante cariz restrictivo bajo el que determinadas propuestas -sobre todo de corte legalista- han acotado su objeto de estudio, llegando este en ocasiones a limitarse al discurso del odio punible donde solo las expresiones y manifestaciones más graves tienen cabida. Cuestión que podía llegar a invisibilizar otros controvertidos escenarios donde los académicos vaticinan auténticos discursos del odio, teniendo una centralidad particular el acontecido en las escuelas y medios digitales. Dos escenarios en 
los que la exposición prolongada y constante por parte de niños y adolescentes a comentarios vejatorios y hostiles, puede desembocar en perniciosos resultados donde la gravedad de cada una de ellas, por separado o en su conjunto, no conforma la dimensión principal o el criterio más apropiado para comprenderlos. Ello ha dado pie a propuestas más flexibles y dinámicas, pero que igualmente han sido objeto de crítica por dilatar enormemente su objeto de estudio al convertirse en aproximaciones más generales y menos precisas. Eso sí, no por ello menos relevantes para nuestra investigación.

Los discursos han sido habitualmente contemplados como proyecciones estandarizadas, estigmatizantes y cargadas de prejuicios hirientes, que persiguen deliberadamente subordinar a un "grupo" mediante actitudes, comentarios o comportamientos vejatorios o humillantes. Son entendidos como la hoja de ruta que vehicula un arsenal argumental peyorativo atravesado por una lógica vertical, jerarquizada y enfrentada -superior / inferior, amigo / enemigo-que moldea la realidad con sus categorías y justifica la aniquilación del otro en todas sus dimensiones -física, moral...-. Esta propuesta es coherente con el planteamiento de Ángela Sierra (2007), quien además complementa dicha aproximación apuntando que "filtran principios, vuelven nítidas las opciones, aclaran las filias y también las fobias, anticipan los pros y los contras, proporcionan argumentos para estar de acuerdo y también razones para el desacuerdo" (p. 8).

Pese a estas vicisitudes y discrepancias, los académicos también sostienen que existen otros parámetros asumibles por el grueso de la literatura académica que, posibilitando cierto orden y coherencia, confieren al concepto una utilidad social que de otro modo podría verse diluida. Nuevamente, Edoardo Bazzaco et al (2018) expresan que:

A pesar de no existir acuerdo sobre la definición exacta de discurso del odio, sí hay acuerdo sobre el hecho de que toda expresión de odio debe de ser discriminatoria contra personas a las que se percibe como diferentes, "los otros”, y que sea así por su razón de origen, religión, género, orientación sexual, u otras características o condiciones personales (p. 9).

Con arreglo a este planteamiento, si bien estimo enteramente justificada la referencia a la otredad periférica como un parámetro vertebral en la comprensión del funcionamiento de los discursos del odio, no considero satisfactoria la fórmula antropocéntrica bajo la cual los académicos la han presentado. Tal convicción se encuentra sustentada en diversas líneas de investigación que de manera elocuente han evidenciado el cómo las retóricas del poder sobre la que se asientan los discursos que analizaremos en las próximas páginas, 
también han arremetido violentamente -y bajo los mismos procedimientoscontra los animales y la naturaleza.

\section{ECOFEMINISMO Y RETÓRICAS DEL ODIO}

El ecofeminismo es un movimiento social y una corriente de pensamiento que ha insistido firmemente en este planteamiento, y que desde su naturaleza crítica e insurreccional, nos invita a repensar cuán injustificado resultaría no comprender gran parte de las exorbitantes atrocidades cometidas en nombre de intereses antropocéntricos como auténticos discursos del odio. Para corroborar esta hipótesis podemos remitir al pensamiento de diferentes investigadoras como Val Plumwood (1993), Carolyn Merchant (1980), Carmen Velayos (2013), Alicia Puleo (2015) o Greta Gaard (1997), quienes han examinado minuciosamente las retóricas del dominio y exclusión de la otredad en el pensamiento occidental, apuntando a que sus diferentes manifestaciones -hacia las mujeres, hacia los homosexuales, hacia otras etnias...- no han de ser entendidas como átomos aislados o partículas disonantes que actúan en diferentes órdenes de realidad sin interaccionar entre sí. El discurso misógino, las actitudes homófobas o las emergentes en virtud de connotaciones raciales -entre otras-, antes que cristalizarse en el sustrato práctico en su forma pura o no contaminada, conforman una aleación estigmatizada que toma partes prestadas de cada uno de sus eslabones orientándolas hacia un objetivo común que arremete de forma indiscriminada contra la totalidad devaluada (Plumwood, 1993). Esta misma línea sigue la investigación de Alicia Puleo (2015) cuando sostiene que en esa masa informe que constituye la otredad se encuentran tanto las mujeres como los animales. Una aglutinación de seres desplazados de los centros de consideración moral que precisamente quedan definidos en virtud de las "carencias" e insuficiencias que manifiestan con respecto a una estructura de corte patriarcal cómodamente posicionada en las relaciones de poder. En estos términos expone que:

La mujer aparece como figura caracterizada por la emocionalidad y la debilidad de la que hay que diferenciarse para ser superior, inconmovible e imperturbable. [...] Mujeres, esclavos y animales son lo Otro de lo Uno. Son definidos por la carencia de aquello considerado superior: el intelecto, el espíritu (Puleo, 2015, pp. 125-28).

En los mismos términos lo ha entendido María José Guerra Palmero (2011) apuntando que, la exclusión de las mujeres, incorpora también en 
su discurso un firme rechazo hacia los animales y hacia la naturaleza en su conjunto sin la cual no puede entenderse. La mujer ha sido construida culturalmente como un ser atávico e irracional, como un ser dependiente de la inmediatez de sus impulsos y de la apetencia insubordinada de sus emociones. Estos parámetros que la acercaban a la naturaleza y a lo animal, y así nos lo hace saber Guerra (2011) apuntando que siempre ha sido "asimilada a la serpiente seductora y venenosa o a la coneja reproductora, tildada de zorra y comparado su discurso con el parloteo del loro" (p. 28).

Pero también del revés. Según argumentan diferentes autores entre los que destacan Pichardo et al. (2013), la simbología e iconografía que ha rodeado a la mujer en Occidente no solo se ha empleado para someterlas a ellas. El estigma de "lo femenino" se extiende hacia otros grupos a los que se pretende menospreciar y humillar, tal y como habitualmente ha sucedido con los homosexuales. En estos términos lo expresa en su investigación a propósito de los discursos homófobos, poniendo claros ejemplos donde si un niño "prefiere hacer ballet en lugar de jugar al fútbol o si se divierte con juegos y juguetes que se marcan como de chicas, se enfrentará a agresiones homófobas -especialmente a través del insulto maricón-" (Pichardo et al., 2013, p. 7).

Val Plumwood, una lógica y pensadora ecofeminista australiana que ya hemos mencionado anteriormente, indica cómo ser más mujer, más naturaleza, más animal, o lo que es lo mismo, ser menos hombre, han sido distintas manifestaciones de una misma construcción cultural sesgada, prejuiciosa y fragmentaria, que según ella, trató de justificar en occidente la superioridad y dominio de unos seres sobre otros. La investigadora afirma que el origen de tal coyuntura ha de rastrearse siglos atrás, en el surgimiento del pensamiento filosófico dualista: un auténtico armazón conceptual jerárquico y vertical que comprende las sustancias que componen la realidad como antagónicas e irreconciliables, y que al tiempo que las sumerge en escalas de valor infundadas, conduce de manera irremediable a un auténtico cisma o fractura ontológica disfrazando sus tendenciosas creencias bajo aparentes verdades de corte apodíctico, inamovibles e indubitables, que legitiman la opresión. Los dualismos -hombre / mujer, hombre / naturaleza, racional / irracional, civilizado / primitivo, mente / cuerpo...- no han de ser entendidos como burdas oposiciones de sustancias. Estos se encuentran estrechamente asociados a formas sistemáticas de dominio y explotación cuya existencia se sostiene en virtud de un rechazo constante del otro (Plumwood, 1993). En los mismos términos lo ha entendido Javier Romero Muñoz remitiendo al pensamiento de Plumwood, exponiendo la importancia de esta lógica del dominio del siguiente modo: 
Hay que tener en cuenta que los dualismos no son simplemente sistemas de ideas abstractas, sino que tienen sus arraigos con la dominación y se vinculan con expresiones y justificaciones sociales y culturales. De esta manera, los conjuntos de dualismos se refuerzan mutuamente impregnando la cultura de una sociedad determinada mediante una línea divisoria que atraviesa todo un sistema conceptual. [...] Como señala Val Plumwood, estos dualismos "deben verse como formando un sistema, una estructura entrelazada” (Plumwood, 1993, p. 43; en Romero, 2021, p. 7).

Las mujeres, la naturaleza, los animales, las minorías -y en suma la otredad periférica en su conjunto- quedaron anquilosadas al par devaluado de esta relación binómica donde su existencia es definida desde la negatividad y distanciamiento que ostentan en relación con el par vencedor: el único merecedor de consideración moral fruto de su magnánima y excelsa esencia.

Cabe estimar, sin embargo, una importante apreciación. Y es que, dado que la investigación de la teórica australiana se dirige enfáticamente a escudriñar las relaciones de dominio hegemónicas en occidente, podría colegirse que no necesariamente detrás de toda expresión de poder puede rastrearse un insidioso e inescrutable discurso del odio. Las diferentes argumentaciones que proponen la superioridad del hombre frente a la mujer, por ejemplo, podrían desembocar en actitudes androcéntricas o paternalistas antes que misóginas. Tal afinamiento si bien puede asumirse hasta cierto punto sin ambages, no resulta del todo convincente para analizar determinados contextos como los discursos supremacistas y aquellos proferidos durante conflictos bélicos -genocidios, dictaduras, conflictos armados, guerras...- que más allá de presentarse como auténticos discursos del poder y del odio, son también enteramente coherentes con la crítica desarrollada por la académica ecofeminista.

Ambos ingredientes -dominio y odio-, pese a que han sido categorías analíticamente distinguidas por la literatura académica, en tales conflictos se funden en un mismo proyecto contra la totalidad, conformando una relación simbiótica y no meramente retroalimentaria. El dominio provee a este último con dispositivos del poder que le permiten transformar sus proyecciones y fantasías teóricas en hechos prácticos, al tiempo que el odio participa en la relación como un motor que ante cualquier sublevación arremete de forma despiadada y automática, impidiendo así que las relaciones de poder puedan verse subvertidas. En la misma línea lo ha entendido Ángela Sierra (2007), quien afirma que en estos casos:

La destrucción del objeto odiado parece ser la mejor garantía. Si realmente se odia, la indiferencia o el rechazo parecen medidas insuficientes porque se vive bajo la posibilidad amenazadora de que el objeto aparezca en el mundo 
cotidiano y no pueda ser sometido a control. El control es uno de los aspectos sintomáticos de las retóricas del odio (p. 8).

Como analizaremos en las próximas páginas, muchos de estos discursos, como el genocida alemán o ruandés, el proferido durante la masacre de Nankín o en la dictadura chilena de Pinochet, son representaciones fidedignas de esta arquitectónica que emplaza a la otredad periférica en un plano de subordinación absoluto. Pero, y más importante, un escenario donde de manera irrefutable el odio hacia los animales actúa como un auténtico sustento sin el que difícilmente pueden entenderse las dinámicas de exclusión de los grupos humanos. La animalización como estrategia deshumanizante en tales acontecimientos no solo nos conducirá a reivindicar el papel de estos seres sintientes en los discursos del odio; también abrirá la puerta a comprender que expresiones cómo "los exterminaremos como ratas", o "los aplastaremos como cucarachas", alcanzan su poder discursivo al transportar un odio previo hacia estos seres, así como los motivos y justificaciones que naturalizan su exterminio (Schuster, 2019).

\section{Discursos Del odio PROYeCtAdos DuRANTE CONFlictos BÉlicos}

La aproximación de Yona Schuster (2019) al genocidio ruandés acontecido el pasado siglo en la región de los Grandes Lagos de África Central (1994), es quizá uno de los ejemplos más representativos que corroboran lo hasta aquí expuesto. En su investigación, Schuster presenta la importancia que ostentaron los medios de comunicación pro-hutu en la construcción del enemigo tutsi, y cómo los discursos que abiertamente incitaban a la violencia contra este último, pretendieron allanar el camino hacia su total exterminio mediante la animalización. Diferentes revistas, programas y emisoras de radio como Televisión Libre des Mille Collines o la revista Kangura son pruebas fehacientes de este conflictivo escenario a las que remite la investigadora. Así lo expone:

En los medios de comunicación prohutu se detectó la asociación de los tutsis con cucarachas, serpientes, ratas, hienas, entre otros [...]. Sin embargo, el referente inyenzi (cucaracha) fue el protagonista de este repertorio [...] Identificar a los tutsis como cucarachas demuestra que la intención de los medios de comunicación era inculcar en los hutus el deseo de perseguirlos hasta aniquilarlos. La animalización era efectiva porque hacía que el asesinato del enemigo fuera más fácil de ejecutar, pues reducía el sentimiento de culpa en los perpetradores; lo convertía en un acto justificado y natural (Schuster, 2019, p. 38). 
Un examen detenido de estas retóricas del odio apunta a que no solo es necesario comprender que entre el hombre y el animal existe una frontera ontológica que los separa y distingue. Además, es necesario que, entre emisor y receptor, se hable un lenguaje universal del odio donde la simbología e iconografía que rodea a las cucarachas sea también compartida. Ambos tienen claro que pueden erradicarlas sin levantar crítica de ningún tipo. El discurso animalizante no parte de cero. Pese a que el odio hacia las ratas y otros seres es también culturalmente construido -sin que ello suponga negar la importancia de argumentaciones de corte innatista que puedan moderar esta hipótesis-, estos discursos del odio dan por sentado que el mensaje no da pie a equívocos o interpretaciones ulteriores. No hace falta enseñar cómo o por qué hay que exterminar a las cucarachas, pues los receptores del discurso ya contaban con los motivos y justificaciones para hacerlo. La estrategia discursiva de la animalización en tal contexto no cobra sentido sin un discurso previo donde hombres y cucarachas no pueden convivir. No hay espacio para la coexistencia. La cohabitabilidad es inadmisible, y ello se expresa en los mismos términos tanto en la persecución de las cucarachas como en los grupos de humanos reducidos a la misma dimensión (Schuster, 2019).

Las implicaciones que de aquí se sustraen no son únicamente aplicables al escenario ruandés, pues su carga explicativa permite aproximarnos a la tónica común bajo la que los discursos en los conflictos bélicos han operado. Prueba de ello es la investigación de Martí Pons (2015) a propósito de la masacre de Nankín cometida por los japoneses en la Guerra en el Pacífico (19371945) que apunta en la misma dirección. Como él mismo indica, los japoneses fueron insistentemente educados para contemplar al enemigo chino como una auténtica plaga que había que erradicar, y así expresa que les enseñaban que "debían de ser tratados como perros, cucarachas o basura. El proceso de animalización llegó a tal punto que entre las tropas niponas se popularizó el uso del término chankoro (cerdo)" (Pons, 2015, p. 47).

Tales afirmaciones quedan claramente ratificadas por el ya mencionado Charles Patterson (2008), quien además refleja cómo los propios japoneses fueron también duramente perseguidos y animalizados durante la II Guerra Mundial. A tenor de lo expuesto, la terminología simiesca se convirtió en el estandarte principal de esta campaña del odio donde estos últimos fueron frecuentemente denominados como "liliputienses monos de dientes salidos y miopes", "monos uniformados", "simios nipones", "japes"-concepto derivado de japanese ape (mono japonés) - o "monos amarillos”. El investigador también remite a otros estudios y aportaciones como las del historiador John Dower (1988), quien ya había recopilado anteriormente algunos de los epítetos animalescos empleados para vilipendiar, menospreciar y humillar al 
enemigo japonés, y que mostraban de manera clara que las imágenes animalizantes iban más allá de su comparación con simios, babuinos o gorilas. Así las cosas, recurrentemente eran designados como "perros, ratones y ratas, víboras y serpientes de cascabel, cucarachas, alimañas o, más indirectamente, el rebaño japonés” (Patterson, 2008, p. 75). Estas y otras caricaturizaciones y proyecciones estigmatizantes eran promocionadas por los medios de comunicación que, tal y como indica Patterson, distorsionaban la cruda y hostil realidad de la guerra transformándola en un satírico objeto de disfrute y entretenimiento. Así expresa que:

En el número de enero del año 1942 la revista inglesa Punch incluyó una caricatura de página entera titulada "La gente simiesca", donde se representaba a monos en la selva, columpiándose con lianas, ataviados con cascos y rifles en bandolera. [...] A finales de 1942 el New Yorker publicó una caricatura que luego llegó a un público más amplio al ser reproducida en el Reader’s Digest. Representaba a soldados de infantería agachados en posición de tiro frente a una espesa jungla llena de monos y varios francotiradores japoneses. [...] La revista de la Infantería de Marina Leatherneck muy gráficamente representaba a los japoneses como grandes y grotescos insectos con ojos rasgados y dientes salidos a los que las tropas estadounidenses debían erradicar (Patterson, 2008, pp. 77-8).

Desde este enfoque, obviar que determinados grupos de animales humanos y no humanos han sido perseguidos a través de una iconografía animal profundamente mancillada, resulta cuanto menos problemático. No obstante, como tendremos oportunidad de atestiguar en el próximo apartado, la explotación animal y las auténticas barbaridades cometidas contra estos en nuestra cultura han sido justificadas desde muy diferentes formas. Esta cuestión dificulta sobremanera una lectura sencilla de nuestro cometido: demostrar la existencia de discursos del odio contra los animales. Así, según expone Gary Francione (2004), lo que algunos describen como tortura animal, otros lo perciben como parámetros necesarios, naturales y asumibles para nuestra supervivencia.

Es por ello que antes de aproximarnos a los discursos del odio específicamente vertidos contra ratas y cucarachas, resulta necesario comprender cuál ha sido la relación entre instrumentalización, explotación y odio en nuestra cultura. Todo ello con la intención de suscitar una reflexión que permita dar respuesta a la siguiente incógnita: si ante unos mismos hechos unos perciben auténticas e innecesarias torturas, tal y como ha sucedido en relación a la experimentación animal o el consumo de animales, ¿ en qué convierte a aquellos discursos que la defienden, justifican y promocionan? 


\section{INSTRUMENTALIZACIÓN, EXPLOTACIÓN Y ODIO}

En la actualidad, y apoyándonos en las investigaciones desarrolladas desde la ética animal por referentes en la disciplina como Oscar Horta (2012) o Steve Best (2015), podemos sostener que gran cantidad de prácticas relacionadas con animales no humanos sobre las que se ha construido nuestra cultura, como la caza y pesca, la ganadería, o la investigación científica, presentan infinidad de implicaciones morales al someter a estos seres sintientes a padecimientos innecesarios, tratamientos crueles y auténticas torturas en vida. La alimentación forzada en la producción de foie gras o la reclusión en jaulas para experimentar con animales que no volverán a pisar la naturaleza a la que acabamos de remitir, son tan solo algunos ejemplos que parecen conformar la norma antes que la excepción. Muchas de estas implicaciones nos pasaron desapercibidas décadas atrás, pero otras proliferaron sin oposición alguna siendo concienzudamente justificadas y toleradas al no querer renunciar a intereses de corte antropocéntrico -generalmente económicos- que de otro modo se hubieran visto comprometidos.

No resulta extraño concebir que, ante una instrumentalización tan exacerbada, hayan surgido sólidas críticas que apuntan en múltiples direcciones tratando de abarcar la totalidad en defensa de estos seres sintientes. Algunas de ellas se han dirigido contra supuestas necesidades fisiológicas, como lo es el consumo de carne, donde encontramos teóricas como Carol Adams (1990) que han puesto de relieve la cruda realidad que se esconde tras las industrias cárnicas. Otros académicos y auténticos referentes en la disciplina como Gary Francione (2004) expresan cómo la tortura animal se encuentra enmascarada bajo argumentaciones instrumentalistas y pragmáticas, que consideran que su explotación queda justificada mediante una comprensión de los animales reducida a meras propiedades del hombre que pueden ser utilizadas para consumo, experimentación, etc. Como explica en su investigación, y como apuntábamos líneas atrás, en las industrias cárnicas se han cometido verdaderos abusos a los que se les ha negado deliberadamente el reconocimiento y estatuto de tortura por parte de sus perpetradores. Más concretamente apunta que:

Los animales destinados al consumo son mutilados de formas que incuestionablemente causan un intenso dolor que catalogaríamos como cruel e incluso como tortura. Estas prácticas, sin embargo, están permitidas porque la agricultura animal se encuentra altamente aceptada e institucionalizada. Además, precisamente aquellos que apoyan tales prácticas no las perciben como tales, sino como actos normales y necesarios (Francione, 2004, p. 16). 
No es ni mucho menos necesario adoptar una posición abolicionista para reprochar las injusticias cometidas en este ámbito, ni tampoco catalogarlas como discursos del odio para desentrañar su conflictiva estructura. Lo que en cualquier caso ha de quedar claro es que no existe un interés de orden superior por el que el hombre pueda justificar cualquier tipo de trato con los animales; es decir, que le permita legitimar los fines y además aproblematizar los medios.

Pero no podemos achacar de manera exclusiva a las industrias el sufrimiento animal provocado en su vertiente gastronómica. Pensemos, por ejemplo, en una práctica que de manera distendida ha frecuentado los hogares de nuestro territorio, como lo es hervir mariscos -moluscos, bivalvos y otros invertebrados- vivos para consumo personal. En este caso, resultaría bastante cuestionable contemplar su génesis desde un impulso orquestado con fines hostiles. No obstante, en términos de sufrimiento, es potencialmente equivalente realizarlo por diversión u odio que por cualquier otro motivo e inclinación. La polémica alcanza una dificultad estratosférica, pues nos permite reflexionar acerca del propósito que realmente tendría reprochar de manera aislada aquellos discursos que invitasen a hervir animales por odio, sin adentrarnos en una crítica mucho más profunda que abarque también a la instrumentalización. Cabe preguntarse si odio e instrumentalización, en su promoción de la tortura, no son sino dos afluentes que desembocan en un mismo resultado pernicioso.

Podemos poner todavía más ejemplos que dinamitan cualquier comprensión aislada de ambos conceptos, donde quizá uno de los más representativos son las prácticas culinarias que determinados internautas publican en las plataformas digitales como YouTube. En ese sentido, la coreana 쏘영 Ssoyoung (s.f.) -un canal con más de 6 millones de suscriptores- publica asiduamente vídeos que difícilmente pueden no ser catalogados como auténticos abusos y torturas. En estos secciona calamares por la mitad, desmiembra gambas y langostinos con sus propias manos, ingiere pulpos, los trocea o incluso los quema en una parrilla. Llega al extremo de propinarles golpes, o verterles salsa mientras estos se retuercen. Insisto, todo ello mientras los animales están aun en vida (쏘영 Ssoyoung, 2019 y 2020 a y b). Pero la actitud de la youtuber es completamente opuesta a la esperada. En sus publicaciones sobreactúa como si de una comedia dramatúrgica se tratase: sonríe constantemente a cámara y disfruta de lo que hace durante todo el vídeo, convirtiendo este en un estrambótico escenario aderezado con música divertida y coloridos y animados carteles en los que explica detalladamente qué y cómo actuará en cada vídeo. Tanto en este último como en los próximos ejemplos a los que atenderemos la complejidad es todavía mayor. Y, ello se debe a que ya no 
apuntamos a supeditar el sufrimiento animal a meras necesidades fisiológicas -teniendo en cuenta que tampoco las hemos justificado en ningún caso-. Los vídeos de 쏘영 Ssoyoung acumulan cientos de millones de reproducciones en su totalidad, convirtiéndose así en un verdadero espectáculo audiovisual donde el sufrimiento animal es buscado premeditadamente para entretener a los espectadores. Un entretenimiento que en ningún caso es ajeno a nuestra cultura.

La tauromaquia es quizá uno de los ejemplos más representativos a la que los investigadores han remitido de manera recurrente para corroborar este planteamiento. Un estremecedor espectáculo que según Violant Doncos et al (2009) adopta la forma de un crimen legal que ha estado promocionado e impulsado en programas de televisión durante años. Esta y otras prácticas cuanto menos cuestionables han convivido en nuestro sustrato social, como lanzar cabras y pavos desde lo alto de un campanario -generalmente a una lona- durante las fiestas de algunos pueblos, y que todavía en la actualidad están debidamente documentadas en diferentes plataformas digitales como la recientemente mencionada. Remontándonos al año 1992, encontramos una publicación donde una jauría de personas en Manganeses de la Polvorosa, al cántico de "la puta de la cabra”, festejan mientras un ejemplar es zarandeado por una soga al cuello desde lo alto de dicha estructura (Miguel G, 2015). Dicha criatura se verá precipitada instantes después para el deleite de un espectador que como hemos indicado, aguardaba con júbilo.

Con el paso de los años se fue sustituyendo -o al menos intentándolo- el empleo de criaturas vivas por muñecos. Cuestión que es predicable de otras fiestas y actividades como el día de los gansos o gansos de Lekeitio que, además, con su visceralidad, pone de relieve cómo el sufrimiento no es el único parámetro alrededor del que orbita la ética animal (eitib, 2013). En la actualidad, ver cómo un ganso muerto es brutalmente degollado en lo que se denominan "alzadas", suscita a todas luces una seria revisión de la relación que tenemos con los seres que nos rodean.

Pese a que desde este punto nos vamos a aproximar al incuestionable discurso del odio hacia determinados animales como las cucarachas y las ratas en YouTube, no podemos perder de vista que su estudio no es ajeno a la instrumentalización y explotación animal. En ese sentido, aunque algunos no consideren la defensa, promoción o justificación de las actividades recientemente expuestas como discursos del odio, cabe preguntarse si acaso esto no puede suceder únicamente si se sostienen criterios subjetivos y argumentos unilaterales que, solo se aplican de manera arbitraria y conveniente para los intereses de una especie en concreto. 


\section{EXTERMINIO DE RATAS Y CUCARACHAS EN LOS MEDIOS DE COMUNICACIÓN}

Como venimos apuntando, el odio hacia las ratas y cucarachas es relativamente sencillo de rastrear. Entre otras cosas, ello se debe a que los propios creadores de contenido publican sus vídeos en esta plataforma bajo títulos como "Golpeando, electrocutando y matando a una cucaracha" (Kevin Danduoro, 2019) o "quemando cucarachas" (Vaporfiend, 2008). Es un escenario en el que, tanto aquel que lo publica como el receptor del vídeo, participan activamente en la construcción del discurso. Detrás de vídeos en los que las cucarachas son calcinadas, abrasadas y perseguidas con sopletes caseros, o aplastadas y golpeadas hasta la muerte, se esconde un impaciente espectador que alienta al primero a continuar deleitándole con "hazañas" cada vez más retorcidas, morbosas y abominables.

No obstante, y como indicamos al comienzo de esta investigación, si bien la comprensión de los vídeos en sí mismos como discursos puede suscitar dudas, los comentarios publicados en estos no parecen seguir la misma tónica. Por tanto, desde este punto, nos pronunciaremos a propósito de los comentarios vertidos en prácticas tan retorcidas como las que se explicarán en las próximas páginas. Sabiendo esto, podemos remitir al canal Funny Experiment (s.f.), que cuenta con diferentes vídeos en los que pega a las cucarachas al suelo y las tortura inyectándoles con una jeringuilla ácido sulfúrico, desinfectante a base de peróxido, o alcohol. Veamos algunos de los comentarios vertidos en esta publicación:

¿Podrías grabar otro cortándoles las antenas o las patas? A mí también me encanta torturar insectos" (Giraffe, 2019), "Por favor, graba uno usando gasolina y prendiéndole fuego con un mechero" (Jad3d, 2020), "Yo venía a verlas explotar" (Gokhen Alter, 2020), "Gracias por hacerle un favor a la humanidad (Hershy 2021), "Ugg la has tocado con las manos" (A Google User, 2021) (en Funny Experiment, 2019).

En la misma línea encontramos otro vídeo en el que el autor se ensaña hasta el extremo de carbonizar a una cucaracha tras más de 30 segundos abrasándola con un soplete (Kõivupuu, 2021). Los comentarios en esta publicación no son muy diferentes al anterior. Podemos destacar algunos de los más distinguidos:

Como alguien que odia profundamente a las cucarachas, esto me llena de éxtasis" (CrimsonTurtle Gaming, 2021), “¿Pueden las cucarachas sentir dolor? Dios, espero que sí” (The Deer Zone, 2021), "Me estaba riendo muchísimo mientras reducías a la cucaracha a átomos" (3T-90AM), "Esto es muy inte- 
resante y entretenido. El sonido de las cucarachas ardiendo es muy relajante" (nwa 4w, 2021), "Odio a los insectos con toda mi alma, por lo que ver esto es muy satisfactorio” (Shikikan KillZone, 2021) (en Kõivupuu, 2021).

Con las ratas son predicables idénticas implicaciones. Así, en "trampas para ratones en acción” (Chris Gilliam Man Stuff, 2020), una recopilación de ejecuciones en vivo de roedores, encontramos nuevamente comentarios hirientes que apuntan también a una retroalimentación entre el creador y el receptor: un disfrute mutuo en el que ambos se alimentan del odio. Tal regocijo se manifiesta claramente en comentarios como los aquí recogidos:

Deberían vender trampas que las aniquilasen de las formas más inhumanas posibles. Algo que de verdad las destrozase por completo" (Omar, 2021), "Gracias por destruir esta plaga" (Father Gabriel Stokes, 2021), "Buen vídeo. Tienes que hacer una segunda parte que dure más (JTO o, 2021) (en Chris Gilliam Man Stuff, 2020).

Tiene que quedar claro que no se trata de vídeos aislados. Bajo la etiqueta de "animal de plaga" se cometen auténticas barbaridades que arremeten de las formas más crueles que uno pueda imaginar. Un auténtico espectáculo que busca premeditadamente cometer la ejecución más retorcida y cruel, y que, cuanto más repulsiva, brutal y desmesurada resulte, más tráfico digital genera. El usuario “The UZ" (s.f.) traslada este caso al extremo llevando más de un año publicando ejecuciones mediante trampas caseras que fabrica él mismo -e invita a crear a los demás-. Un ejemplo bastante representativo publicado en su canal consiste en un mecanismo rotatorio vertical tensado con potentes gomas elásticas y cargado con afilados clavos. Una vez el ratón muerde el cebo, se activa una palanca con objetos punzantes que lo atraviesan y levantan haciéndolo girar al tiempo que lo estampan contra un bloque de madera cada vez que el mecanismo da una vuelta de $360^{\circ}$. Finalmente, cuando las gomas se destensan por completo, el ratón queda suspendido en el aire con la boca y un ojo atravesado formando una pompa de sangre (The Uz, 2021a). Tal vídeo es nuevamente alabado por muchos de sus fieles seguidores. Así se lo hacen saber:

Esta es una de las mejores trampas que has hecho [...] Me encanta cómo has conseguido que la trampa empale al ratón con los clavos, y que con el mecanismo rotatorio sea golpeado contra la madera y lo atraviese aun más profundo. Me encanta tu contenido, sigue así" (Jonathan Yang, 2021a). "Llámame raro, pero me reído un montón cuando finalmente el ratón queda atravesado" (Glover King, 2021) "Es una buena trampa si quieres ver toda tu casa cubierta 
de sangre de ratón” (Jim Domoradzki, 2021). “QQué precisión! Un clavo le atravesó el ojo y el otro la boca. ¡Épico!” (Jonathan Yang, 2021b) (en The Uz, 2021a).

Por una cuestión de espacio resulta completamente inabarcable analizar una por una las diferentes manifestaciones de estos discursos, pero todos ellos apuntan hacia la aniquilación de los ratones empleando cualquier medio posible, y cuanto más llamativo, doloroso y sanguinolento, mejor. Sin embargo, no podemos olvidar que el exterminio de animales ha contado -y sigue contando- en nuestra cultura con un sólido apoyo promocionado incluso en la televisión y medios de comunicación tradicionales. Y además, no lo han publicitado de manera neutral ni procurando que este se produjese de la manera menos intrusiva y dañina posible. Muy al contrario, un comercial de la famosa marca Raid (2021) cuyo lema es "Los mata bien muertos, protege a tu familia”, es uno de los ejemplos más claros cuya simbología es aplicable a los diferentes anuncios de la misma temática. Comienza del siguiente modo:

Las cucarachas... Nadie quiere verlas, y si las ves, quieres librarte de ellas porque donde hay una muchas más pueden acechar en las sombras. No solo es su apariencia desagradable, sino que además llevan suciedad y heces a la superficie de todo tu hogar (Raid lationoamérica, 2021).

Más extensamente, las cucarachas siempre han sido presentadas en los anuncios como seres putrefactos, desaliñados y con apariencia mugrienta y sucia. Otro comercial de la misma marca donde las dos protagonistas son apodadas "sucia rachita" y "racha rastrera" -conceptos provenientes del término cockroach en inglés- apunta en la misma dirección (Entretenimiento y Comerciales, 2016).

Si en este punto su comprensión como discurso del odio resulta problemática, se debe a que tras estos anuncios existe un claro espíritu por banalizar el exterminio animal. Cuando se caricaturiza a las cucarachas y otros insectos mediante dibujos animados en los anuncios, se pretende crear un proyecto eufemístico que esconda la realidad de lo que sus productos realmente producen. Y, de este modo, se convierten en un enmascaramiento edulcorado del exterminio. No se dirigen de forma honesta al espectador mostrándole qué hay detrás del veneno que descompondrá los intestinos de la rata que lo devore, o que arrasará con todo rastro de vida a su paso. Sin embargo, pese a que no se percibe la misma explicitud que en los casos analizados anteriormente en YouTube, los resultados que produce no son tan dispares. 
La problemática se torna ya prácticamente insondable si además comprendemos que tal instrumental -insecticidas, pesticidas y raticidas anunciados- también es aprovechado por otros internautas que en sus vídeos expresan el odio que sienten hacia tales criaturas. Esta cuestión invita cuanto menos a la reflexión, y es que, con independencia de si uno considera los anuncios televisivos que promueven el exterminio como verdaderos discursos del odio, sus medios comercializados son empleados también para el disfrute del espectador y del creador del vídeo que se recrean con sus resultados. Como hemos apuntado en el apartado anterior, odio e instrumentalización no son realidades tan disímiles ni en cuanto a los fines buscados, ni en relación a los medios empleados, $\mathrm{y}$, ni mucho menos, al daño y sufrimiento que se permiten provocar.

Para finalizar, contemplamos un último caso que corrobora lo hasta aquí expuesto. Se trata de un vídeo donde el autor comienza sosteniendo el profundo odio que siente hacia las cucarachas, estimando que estas sean, con casi toda seguridad, una de las criaturas más desagradables del planeta (leokimvideo, 2017). Vídeo en el que, tras capturar un ejemplar -suceso que ya de por sí debería contemplar su exterminio como innecesario, dado que estando atrapada no puede generar ningún supuesto "mal"-, procede a rociarle insecticida por encima. En esta publicación encontramos los siguientes comentarios: "Estás haciendo un trabajo fantástico. Que Dios te bendiga" (Fatmooselips 31, 2018) "No eres el único que odia a las cucarachas, yo también lo hago" (Drew Thornton, 2019), "Mi solución contra las cucarachas: alcohol y un mechero" (huy luu, 2019) (en leokimvideo, 2017).

\section{Conclusiones}

Invisibilizar al otro contemplándolo como algo distinto y alejado de consideración moral de cualquier tipo es, sin duda, uno de los ejercicios más comunes y eficaces empleados desde las retóricas del odio. No obstante, a la hora de analizar los discursos dirigidos contra los animales la problemática se acentúa, y ello se debe a que la instrumentalización y explotación cuentan en este contexto con un consistente apoyo tanto a nivel institucional como social. Tal y como indica Francione (2004), muchas de las atrocidades que cometemos contra los animales han quedado legitimadas apelando a una supuesta "necesidad" de orden superior que, desde un espectro puramente subjetivo y conveniente para nuestra especie, sitúa nuestros intereses incluso por encima de la barbarie. Es decir, ateniéndonos a su planteamiento, nos encontramos ante la problemática de que prácticamente cualquier acto, por 
muy cruel, vil o despótico que nos resulte, puede quedar justificado si se opone ante un interés de corte antropocéntrico lo suficientemente respaldado culturalmente.

Uno de los escenarios donde con mayor claridad puede contrastarse esta hipótesis lo encontramos, como ya hemos visto, en las industrias cárnicas $-\mathrm{y}$ más concretamente en los mataderos-, donde la servidumbre de estos seres sintientes alcanza cuotas estratosféricas. En este punto, podemos retomar el pensamiento de Charles Patterson (2008) cuando remite a una de las más célebres citas de Theodor Adorno que corrobora este planteamiento, y desde donde se entiende que instrumentalización, explotación y odio, presentan en nuestra sociedad una estrechísima relación. Así expone que "Auschwitz empieza cuando uno mira a un matadero y piensa: son sólo animales" (traducción de Blanke, 1995, p. 48) (en Patterson, 2008, p. 96).

A tenor de lo expuesto, recriminar la existencia de auténticos discursos del odio vertidos específicamente contra los animales, supone un punto de inflexión que aspira a revertir las profundas incoherencias internas de una cultura fuertemente especista que, al tiempo que afirma oponerse seriamente ante determinadas formas de exclusión y rechazo, incuba en lo más hondo de su ser un categórico desprecio e indiferencia ante otras formas de abuso y tortura. Por ello, desde esta investigación se apuesta por una reflexión crítica que no desemboque en un enclave conformista y selectivo que únicamente se oponga ante las manifestaciones más explícitas y nauseabundas imaginables en tanto que estas no interfieran con sus privilegios e intereses. Precisamos de un frente que se oponga eficazmente ante determinados actos sumamente deleznables como la tauromaquia o los vídeos de YouTube aquí expuestos, pero que al mismo tiempo no se encuentre inerme ante prácticas rutinarias en los mataderos como las técnicas halal o kosher-entre otras-donde se expone a los animales a un sufrimiento exacerbado.

En suma, si apostamos por una perspectiva más horizontal e inclusiva que nos permita erradicar los discursos del odio y sus funestas consecuencias de nuestra sociedad, no podemos obviar en ningún caso que nuestra relación con los animales ha estado -y está- profundamente atravesada por la esclavitud y la servidumbre.

\section{REFERENCIAS}

AdAms, C. (1990). La política sexual de a carne. Una teoría crítica feminista vegetariana. Madrid, Ochodoscuatro ediciones, 2016 (traducción del equipo editorial). 
Bazzaco, E. y Juanatey, A. y Lejardi, J. y Palacios, A. y Tarragona, L. (2018). ¿ Es odio? Manual práctico para reconocer y actuar frente a discursos y delitos de odio. Barcelona, Institut de Drets Humans de Catalunya, SOS Racisme Catalunya.

BEST, S. (2015). Los zoológicos y el fin de la naturaleza. Resistencia AntiEspecista y Kanaj Ediciones.

Blanke, C. (1995). Da krähte del Hahn: Kirche für Tier? Eine Streitschrift. Eschbach, Verlag am Eschbach.

Chris Gilliam Man Stuff, C. G. (2020, 19 de Noviembre). Mouse Traps in Action [Vídeo]. YouTube. https://www.youtube.com/watch?v=HvwIFkySGCg\&ab_ channel=ChrisGilliamManStuff (última consulta: 25.07.2021).

- Comentarios citados en esta publicación:

Father Gabriel Stokes en Chris Gilliam Man Stuff. (2020, 19 de Noviembre). Mouse Traps in Action [Vídeo]. YouTube. https://www.youtube.com/ watch?v=HvwIFkySGCg\&ab_channel=ChrisGilliamManStuff

JTO o en Chris Gilliam Man Stuff. (2020, 19 de Noviembre). Mouse Traps in Action. [Vídeo]. YouTube https://www.youtube.com/watch?v=HvwIFkySGCg\&ab_ channel=ChrisGilliamManStuff

Omar en Chris Gilliam Man Stuff. (2020, 19 de Noviembre). Mouse Traps in Action. [Vídeo]. YouTube https://www.youtube.com/watch?v=HvwIFkySGCg\&ab_ channel=ChrisGilliamManStuff

CrimsonTurtle Gaming, en Kõivupuu. (2021, 9 de febrero). When the cockroach comes out to play:) [Video]. YouTube. https://www.youtube.com/ watch? $=$ Yq8o4vkDBY4\&ab_channel=K\%C3\%B5ivupuu (última consulta: 25.07.2021).

eitb. (2013, 6 de septiembre). Vídeo: Gansos de Lekeitio 2013, todo tipo de alzadas [Vídeo]. YouTube. https://www.youtube.com/watch?v=sPZ7GBLW2y8\&t=63s \&ab_channel=eitb (última consulta: 25.07.2021)

Entretenimiento y Comerciales. (2016, 24 de octubre). RAID MAX 'Trailers de Cucarachas' (2016) [Vídeo]. YouTube. https://www.youtube.com/ watch? $\mathrm{v}=\mathrm{zR}$ 7LsnrV-OI\&ab_channel=EntretenimientoyComerciales (última consulta: 25.07 .2021$)$

Francione, G. (2004). “Animals-Property or Persons?”. Rutgers Law School (Newark), 21, pp. 1-45.

Funny Experiment. (s. f). Inicio [Canal de YouTube]. YouTube. Recuperado el 5 de Junio de 2021, de Funny Experiment - YouTube (última consulta: 25.07.2021)

Funny Experiment. (2019, 6 de Junio). [Kill cockroaches series]The first: What happens when a cockroach is injected [Video]. YouTube. https://www.youtube.com/ watch?v=ydggGSJcDCY\&ab_channel=FunnyExperiment (traducción personal) (última consulta: 25.07.2021).

- Comentarios citados en esta publicación:

Giraffe en Funny Experiment. (2019, 6 de junio). [Kill cockroaches series] The first: What happens when a cockroach is injected [Video]. YouTube. https://www. 
youtube.com/watch?v=ydggGSJcDCY\&ab_channel=FunnyExperiment (traducción personal).

Gokhen Alter en Funny Experiment. (2019, 6 de junio). [Kill cockroaches series] The first: What happens when a cockroach is injected [Video]. YouTube. https:// www.youtube.com/watch?v=ydggGSJcDCY\&ab_channel=FunnyExperiment (traducción personal).

Google User en Funny Experiment. (2019, 6 de junio). [Kill cockroaches series] The first: What happens when a cockroach is injected [Video]. YouTube. https:// www.youtube.com/watch?v=ydggGSJcDCY\&ab_channel=FunnyExperiment (traducción personal).

Hersh en Funny Experiment. (2019, 6 de junio). [Kill cockroaches series] The first: What happens when a cockroach is injected [Video]. YouTube. https://www. youtube.com/watch?v=ydggGSJcDCY\&ab_channel=FunnyExperiment (traducción personal).

GAARD, G. (1997). “Toward a queer Ecofeminism”. Hypatia, 12, pp. 137-156.

Guerra, Palmero, M. J. (2011). "La (des)conexión mujeres y naturaleza”. Icono14, 9, pp. 21-38.

HorTA, O. (2012). “Tomándonos en serio la consideración moral de los animales: más allá del especismo y el ecologismo". En Animales no bumanos entre animales bumanos, editado por Jimena Rodríguez Carreño, pp. 191-226. Madrid, Plaza y Valdés.

Jay, Gould, S. (2003). La falsa medida del hombre. Barcelona, Crítica.

Jonathan, Tang, en the UZ. (2021, 5 de Febrero). Spear Super Mouse Trap / rat trap, rotating mouse trap [Vídeo]. YouTube. https://www.youtube.com/ watch?v=YaOO2N04UfY\&ab_channel=theUZ (traducción personal) (última consulta: 25.07.2021).

Danduoro, K. (2019, 18 de febrero). Smashing, Electrocute E Killing The Cockroach - 14 February 2019 [Vídeo]. YouTube. Smashing, Electrocute \& Killing The Cockroach - 14 February 2019 - YouTube (última consulta: 25.07.2021)

Kovacevic, D. (2017). "La animalización como mecanismo de deshumanización en la dictadura militar chilena (1973-1990)". Revista Lationamericana de Estudios Críticos Animales, vol. 1, pp. 151-179.

Kõivupuu. (2021, 9 de Febrero). When the cockroach comes out to play [Vídeo]. YouTube. https://www.youtube.com/watch?v=Yq8o4vkDBY4\&ab_ channel=K\% C3\%B5ivupuu (última consulta: 25.07.2021).

- Comentarios citados en esta publicación:

CrimsonTurtle Gaming en Kõivupuu. (2021, 9 de febrero). When the cockroach comes out to play [Vídeo]. YouTube. https://www.youtube.com/ watch?v=Yq804vkDBY4\&ab_channel=K\%C3\%B5ivupuu

KillZone en Kõivupuu. (2021, 9 de febrero). When the cockroach comes out to play [Vídeo]. YouTube. https://www.youtube.com/watch?v=Yq8o4vkDBY4\&ab_ channel=K\% $3 \%$ B5ivupuu 
nwa 4w en Kõivupuu. (2021, 9 de febrero). When the cockroach comes out to play [Vídeo]. YouTube. https://www.youtube.com/watch?v=Yq8o4vkDBY4\&ab_ channel=K\% C3\%B5ivupuu

The Deer Zone en Kõivupuu.(2021, 9 defebrero). When the cockroach comes out toplay

[Vídeo]. YouTube. https://www.youtube.com/watch?v=Yq8o4vkDBY4\&ab_ channel=K\% C3\%B5ivupuu

Leokimvideo. (2017, 15 de junio). Giant Cockroach Vs Mortein Rapid Kill Bug Spray Does It Work [Vídeo]. YouTube. https://www.youtube.com/ watch?v=7ZLqwN6a55M\&ab_channel=leokimvideo (traducción personal) (última consulta: 25.07 .2021$)$

- Comentarios citados en esta publicación:

Drew Thornton en leokimvideo. (2017, 15 de junio). Giant Cockroach Vs Mortein Rapid Kill Bug Spray Does It Work [Vídeo]. YouTube. https://www.youtube. com/watch?v=7ZLqwN6a55M\&ab_channel=leokimvideo (traducción personal)

Fatmooselips 31 en leokimvideo. (2017, 15 de junio). Giant Cockroach Vs Mortein Rapid Kill Bug Spray Does It Work [Vídeo]. YouTube. https://www.youtube. com/watch?v=7ZLqwN6a55M\&ab_channel=leokimvideo (traducción personal)

huy luu en leokimvideo. (2017, 15 de junio). Giant Cockroach Vs Mortein Rapid Kill Bug Spray Does It Work [Vídeo]. YouTube. https://www.youtube.com/ watch?v=7ZLqwN6a55M\&ab_channel=leokimvideo (traducción personal).

Merchant, C. (1980). The Death of Nature: Women, Ecology, and the Scientific Revolution. San Francisco: Harper \& Row Publishers.

Miguel G. (2015, 26 de septiembre). Paletadas - Pateo de la Cabra en Manganeses de la Polvorosa [25-01-1992] [Vídeo]. YouTube. https://www.youtube.com/ watch?v=8Zf7faJX0yE\&ab_channel=MiguelG (última consulta: 25.07.2021).

Mínguez, Violant, D. y Ramallete, Esteban, C. y Gual, Ortiz, G. (2009). La tortura como espectáculo. (Trabajo de Fin de Grado). <https://ddd.uab.cat/record/80140> [consulta: 08.07.2021].

NeIl D en, How Mouse Trap. (2019, 29 de Agosto). Glue Trap Mice - Top 1 glue trap - Homemade mouse trap [Vídeo]. YouTube. https://www.youtube. com/watch?v=Yu7KznIco_4\&ab_channel=HowMouseTrap (última consulta: 25.07.2021).

OgG, B. y OgG, C. y Ferraro, D. y Jefferson, D. (2006). Manual para el control de cucarachas. Lancaster County: University of Nebraska-Lincoln.

Omar, en Chris Gilliam Man Stuff. (2020, 19 de noviembre). Mouse Traps in Action [Vídeo]. YouTube. https://www.youtube.com/watch?v=HvwIFkySGCg\&ab_ channel=ChrisGilliamManStuff (última consulta: 25.07.2021).

PAtTerson, C. (2008). ¿Por qué maltratamos tanto a los animales? Un modelo para la masacre de personas en los campos de exterminio nazis. Lleida, Milenio.

Pichardo, G. J. y Molinuevo, B. y Medina, P. y Martín, N. y López, M. (2013). “Actitudes ante la diversidad sexual de la población adolescente de Coslada (Madrid) y San Bartolomé de Tirajana (Gran Canaria)”. En Ministerio de Educación (ed.), 
Premios Nacionales de Investigación Educativa y Tesis Doctorales 2007, pp. 287320, Madrid: Ministerio de Educación.

Plumwood, V. (1993). Feminism and the Mastery of Nature. Taylor \& Francis eLibrary.

Pons, VÁzquez, M. (2015). El camino hacia la barbarie: historia contemporánea del Imperio de Japón y su relación con las atrocidades en la guerra del pacífico. (Trabajo Fin de Grado). Barcelona, Universitat Pompeu Fabra. Barcelona.

Puleo, A. (2015). Ese oscuro objeto del deseo: cuerpo y violencia. Investigaciones Feministas, vol. 6, núm. 122, pp. 122-138. https://doi.org/10.5209/rev_INFE.2015. v6.51383

Raid Lationamérica. (2021, 31 de marzo). Raid MAX® - Mata cucarachas! [Vídeo]. YouTube. https://www.youtube.com/watch?v=PIdGtMjkC4k\&ab_ channel=RaidLatinoam\%C3\% A 9rica (última consulta: 25.07.2021).

Romero, J. (2021). "Comprender la "lógica del dominio": la perspectiva ecofeminista de Val Plumwood como eje transversal en los estudios de género". Cuestiones transversales relativas a la innovación en la docencia y en la investigación de las ciencias sociales y jurídicas. Madrid, Dykinson, S.L., (en imprenta).

SCHUSTER, López, Y. (2019). El poder asesino de la palabra:papel de los medios de comunicación en la promoción de la violencia en conflictos entre butus y tutsis de la región de los Grandes Lagos en África Central. (Trabajo Fin de Grado). Bogotá, Universidad Pontificia Javeriana, Bogotá.

Sierra González A. (2007). "Los discursos del odio". Cuadernos del Ateneo, 24, pp. 5-17.

Tye Uz. (s. f). Inicio. [Canal de YouTube]. YouTube. Recuperado el 5 de Junio de 2021, de the UZ - YouTube (última consulta: 25.07.2021).

The Uz.(2021a, 5 defebrero). Spear Super Mouse Trap / Rat Trap, Rotating Mouse Trap [Vídeo]. YouTube. https://www.youtube.com/watch?v=YaOO2N04UfY\&t=2s \&ab_channel=theUZ (última consulta: 25.07.2021).

- Comentarios citados en esta publicación:

Glover King en The Uz. (2021a, 5 de Febrero). Spear Super Mouse Trap / Rat Trap, Rotating Mouse Trap [Vídeo]. YouTube. https://www.youtube.com/ watch? $=$ YaOO2N04UfY\&t=2s\&ab_channel=theUZ

Jim Domoradzki en The Uz. (2021a, 5 de Febrero). Spear Super Mouse Trap / Rat Trap, Rotating Mouse Trap [Vídeo]. YouTube. https://www.youtube.com/ watch? $\mathrm{v}=\mathrm{YaOO} 2 \mathrm{~N} 04 \mathrm{UfY} \& \mathrm{t}=2 \mathrm{~s} \& \mathrm{ab} \_$channel=theUZ

Jonathan Yang en The Uz. (2021a, 5 de Febrero). Spear Super Mouse Trap / Rat Trap, Rotating Mouse Trap [Vídeo]. YouTube. https://www.youtube.com/ watch $? \mathrm{v}=\mathrm{YaOO} 2 \mathrm{~N} 04 \mathrm{UfY} \& \mathrm{t}=2 \mathrm{~s} \& \mathrm{ab} \_$channel=theUZ

TheUZ.(2021b,30de enero). Mouse Trap, Making ADangerous Mouse Trap With Nails [Vídeo]. YouTube. https://www.youtube.com/watch?v=auuNWCUCE9k\&ab_ channel=theUZ (última consulta: 25.07.2021).

Velayos Castelo, C. (2013). La frontera animal-humano. Arbor, 189(763), a065. https://doi.org/10.3989/arbor.2013.763n5002. 
VAPORFIEND. (2008, 24 de noviembre). Cockroach flambe [Vídeo]. YouTube. https:// www.youtube.com/watch?v=1j2UoIRuaQk\&ab_channel=vaporfiend (última consulta: 25.07 .2021$)$

Wilderness xyz. (2019b, 29 de agosto). Most creative, Most amazing wooden mouse trap, New type of mousetrap, using wood and rubber band [Vídeo]. YouTube. https://www.youtube.com/watch?v=bgbxybo7Di8\&t=2s\&ab_channel=wilder nessxyz (última consulta: 25.07.2021)

쏘영 Ssoyoung. (s. f). Inicio [Canal de YouTube]. YouTube. Recuperado el 2 de Mayo, de 2021, de https://www.youtube.com/c/Ssoyoung/featured (última consulta: 25.07 .2021$)$

쏘영 Ssoyoung. (2020a, 7 de febrero). ENG SUB) Dancing Live Squid (Raw Squid + Braised Squid) Eating Sound Ssoyoung [Vídeo]. YouTube. https://www.youtube.com/watch?v=Y3qELp9F9dI (última consulta: 25.07.2021)

쏘영 Ssoyoung. (2020b, 30 de enero). ENG SUB) Octopus \& mudfish Mukbang Eatingsound Seafood Ssoyoung [Vídeo]. YouTube. https://www.youtube.com/ watch? $=\mathrm{NcChbIdrdaA}$

쏘영 Ssoyoung. (2019, 19 de octubre). ENG SUB) The Most Crazy Raw Shrimp Mukbang Eatingsound Realsound [Vídeo]. YouTube. https://www.youtube. $\mathrm{com} /$ watch?v=PbRn5_johZg\&ab_channel=\%EC\%8F\% 98\%EC\% 98\%81Ssoy oung (última consulta: 25.07.2021) 